Ann. Geophysicae 18, 1-10 (2000) ㄷ EGS - Springer-Verlag 2000

\title{
Simultaneous auroral observations described in the historical records of China, Japan and Korea from ancient times to AD 1700
}

\author{
D. M. Willis ${ }^{1, *}$, F. R. Stephenson ${ }^{2}$ \\ ${ }^{1}$ Space and Astrophysics Group, Department of Physics, University of Warwick, Coventry CV4 7AL, UK \\ ${ }^{2}$ Department of Physics, University of Durham, Durham DH1 3LE, UK
}

Received: 21 May 1999 / Revised: 20 August 1999 / Accepted: 26 August 1999

\begin{abstract}
Early auroral observations recorded in various oriental histories are examined in order to search for examples of strictly simultaneous and indisputably independent observations of the aurora borealis from spatially separated sites in East Asia. In the period up to AD 1700, only five examples have been found of two or more oriental auroral observations from separate sites on the same night. These occurred during the nights of AD 1101 January 31, AD 1138 October 6, AD 1363 July 30, AD 1582 March 8 and AD 1653 March 2. The independent historical evidence describing observations of mid-latitude auroral displays at more than one site in East Asia on the same night provides virtually incontrovertible proof that auroral displays actually occurred on these five special occasions. This conclusion is corroborated by the good level of agreement between the detailed auroral descriptions recorded in the different oriental histories, which furnish essentially compatible information on both the colour (or colours) of each auroral display and its approximate position in the sky. In addition, the occurrence of auroral displays in Europe within two days of auroral displays in East Asia, on two (possibly three) out of these five special occasions, suggests that a substantial number of the mid-latitude auroral displays recorded in the oriental histories are associated with intense geomagnetic storms.
\end{abstract}

Key words. Magnetospheric physics (auroral phenomena; storms and substorms)

* Also Honorary Research Associate, Rutherford Appleton Laboratory, Chilton, Didcot, Oxon OX11 0QX, UK; and Visiting Reader in Physics, University of Sussex, Falmer, Brighton BN1 9QH, UK

Correspondence to: D. M. Willis

\section{Introduction}

This study discusses the very few known examples of early oriental observations of the aurora borealis from multiple geographic locations on the same night. Such simultaneous observations of the aurora borealis from spatially separated sites in East Asia are understandably rather rare. In the background historical research for this study, a wide variety of sources have been examined: the catalogue of ancient auroral observations from China, Korea and Japan (193 BC-AD 1770) published by Yau et al. (1995); the extensive compilation of early Chinese astronomical records (895 BC-AD 1911) by Beijing Observatory (1988); the Japanese historical records of celestial phenomena since AD 1600 (Osaki, 1994), supplemented by a paper on ancient aurorae seen in Japan (Matsushita, 1956); and the Korean chronicles, which have been searched independently. Nevertheless, only five examples of multiple auroral observations from East Asia have been found in the interval of nearly 2000 years from $193 \mathrm{BC}$ to AD 1700. These multiple auroral observations, which are undoubtedly simultaneous and independent, occurred during the nights of $\mathrm{AD} 1101$ January 31, AD 1138 October 6, AD 1363 July 30, AD 1582 March 8 and AD 1653 March 2. Four further similar events occurred in the interval AD 1700-1900 but some of the associated oriental (and occidental) historical records are so extensive that they merit separate consideration. Therefore, these four similar events will be presented in a subsequent work, in which the rich variety of the historical auroral descriptions can be discussed fully.

The observations on the night of AD 1101 January 31 are remarkable in the sense that the aurora borealis was observed simultaneously and independently from three well-separated sites located in China, North China (there were two separate Chinese empires at this time) and Korea. These particular auroral observations constitute the earliest example yet known of an auroral "triangulation experiment", albeit conducted fortuitous- 
ly. Only a few decades later, on the night of AD 1138 October 6, the aurora borealis was observed simultaneously and independently from sites in China and Korea. The aurora borealis was definitely observed on the following night from at least one site in England and may also have been observed on the same night as in East Asia from at least one site in Eastern Europe. After the lapse of more than two centuries, on the night of $\mathrm{AD}$ 1363 July 30, the aurora borealis was observed simultaneously and independently from sites in China and Japan. More than two centuries later still, on the night of $\mathrm{AD} 1582$ March 8, the aurora borealis was observed simultaneously and independently from sites in China and Japan. On this occasion, the aurora borealis was definitely observed two nights earlier from several sites in Europe and there is some evidence that it was also observed in Europe on the same night as in East Asia. Finally, on the night of AD 1653 March 2, the aurora borealis was observed simultaneously and independently from sites in China and Japan.

The simultaneous occurrence of occidental and oriental observations of the aurora borealis has been discussed previously by Keimatsu et al. (1968) and by Fukushima et al. (1987). For occidental and oriental auroral observations recorded in early centuries (up to about AD 900), Keimatsu et al. (1968) state explicitly that they assumed some observations recorded in the same year actually occurred on the same date, even if there is no definite historical evidence for this assumption. For occidental and oriental auroral observations in later centuries (from about AD 900), these authors used only observations that occurred on exactly the same date. Subsequently, Fukushima et al. (1987) assumed that occidental and oriental auroral observations were essentially simultaneous if they occurred within two days of each other. These authors were concerned primarily, however, with the possibility of using simultaneous auroral observations in East Asia and Europe to determine the secular variation in the direction (or inclination) of the geomagnetic dipole axis over historical time. Keimatsu et al. (1968) presented five examples of simultaneous occidental and oriental auroral observations. The last of these events occurred during the night of $\mathrm{AD} 1138$ October 6, which is the second example we discuss. However, Keimatsu et al. (1968) made no mention of the fact that on this occasion the aurora borealis was also observed from a site in Korea, as well as from one in China. This omission was subsequently rectified by Fukushima et al. (1987), who presented seven examples of simultaneous occidental and oriental auroral observations.

The first two examples presented by Fukushima et al. (1987) are the same as the last two presented by Keimatsu et al. (1968). In addition, the second and fifth examples considered by Fukushima et al. (1987), which occurred on the nights of $\mathrm{AD} 1138$ October 6 and $\mathrm{AD}$ 1582 March 8, are the second and fourth examples discussed here. However, the prime purpose of the present work is to provide some initial assessment of the reliability of the ancient oriental auroral records. In this latter context, our study forms part of an ongoing critical assessment of the reliability and utility of the sunspot and auroral observations recorded in various oriental histories (see Willis et al., 1996a, b). If they can be validated, the oriental sunspot and auroral records are potentially of considerable value in determining possible variations of solar activity during the past two millennia.

Simultaneous ancient observations of the aurora borealis from separated sites in East Asia are extremely important scientifically for several reasons. In particular, simultaneous oriental observations provide virtually incontrovertible evidence that auroral displays actually occurred on these rare occasions. This conclusion follows from the improbability of exactly the same tropospheric phenomenon being observed simultaneously from two widely separated sites. Moreover, there is good agreement between the detailed descriptions of the auroral displays on each of the five nights during which simultaneous observations were recorded. The absolute reliability of the oriental auroral records on such rare occasions tends to confirm their reliability at other times. In addition, the simultaneous observation of occidental and oriental auroral observations on the same night, or on contiguous nights, tends to confirm the overall reliability of the oriental (and occidental) astronomical records in general.

Nevertheless, a particularly remarkable circumstance is the very large number of Korean records between about $\mathrm{AD} 1510$ and 1560 and again for several years around AD 1625 . These follow a very repetitive style, in which the phenomenon observed is usually likened to either a "fire", a "vapour like fire", a "flame" or a "vapour like a flame" (Yau et al., 1995), occurring predominately in the southern sky (Zhang, 1985). (Plural equivalents of these terms are used in the translation of the associated historical records if more than one compass direction is cited.) The Korean observations seemingly correspond to relatively faint, and sometimes featureless, red auroral emissions. At these relatively recent epochs, the range of corrected geomagnetic latitudes appropriate to Korea was probably similar to that at the present time, namely about $25^{\circ}-38^{\circ}$ (Gustafsson et al., 1992), or perhaps even a little closer to the equator (Oguti, 1993a). Therefore, the expected frequency of bright aurorae in Korea should be no more than about once in ten to twenty years (Fritz, 1881; Vestine, 1944). In fact, the available evidence on the secular variation of the auroral zone indicates that Korea would not have been at either auroral or subauroral latitudes at any time during the last thousand years (Oguti, 1993a, b; Oguti and Egeland, 1995). This inference is based primarily on a reasonably realistic model for the secular variation of the total geomagnetic field (not just the dipolar part) over the past millennium.

As yet, no entirely convincing explanation has been given for the huge excess of Korean sightings around the two particular periods mentioned previously, although Zhang (1985) has suggested that most of the Korean records referring simply to a "fire" or a "flame" actually 
describe stable auroral red arcs (SAR arcs). Use of the term "fire" could possibly imply a featureless red auroral emission, which would be consistent with the concept of a SAR arc extending over a large longitudinal distance for a long time and usually being sighted towards the north from East Asia. Conversely, use of the term "flame" could possibly imply a localized but variable subauroral red emission, which often actually has the shape of a flame (or torch) and exhibits dynamic movement. However, it is also possible that the term "flame" was used by the historiographers simply as a synonym for the term "fire". Nevertheless, if these "red" emissions were really associated with auroral displays, the level of auroral activity must have been high because the emissions were frequently seen in the southern sky from Korea (Zhang, 1985). It is then difficult to understand why there are no corresponding auroral records from China and Japan. Indeed, the lack of corresponding records from China, Japan and Europe may indicate that these particular red emissions were local phenomena in Korea and not any kind of global aurora. Alternatively, the Korean observers might have been especially assiduous in watching the night sky for celestial events and hence very diligent in reporting faint aurorae (Dai and Chen, 1980; Zhang, 1985).

The interesting suggestion that most of the Korean records referring simply to a "fire" or a "flame" describe SAR arcs (Zhang, 1985) has been questioned by Kozyra et al. (1997) because of the low intensities that are typical of SAR arcs. During the past three solar cycles (20-22), the average intensity of the 630-nm ("red-line") emission from excited atomic oxygen in the ${ }^{1} D$ state has been about several hundred Rayleighs (R) for typical SAR arcs (Kozyra et al., 1997). To be visible to the unaided eye, the SAR arcs allegedly observed by the Korean observers must have achieved intensities of at least 6$10 \mathrm{kR}$. Such intensities were virtually unrecorded during Solar Cycle Number 22, although average intensities of 6 $\mathrm{kR}$ were reported near the maximum (1957.9) of Solar Cycle Number 19 (Roach and Roach, 1963). Therefore, the attempt by Zhang (1985) to explain the huge excess of Korean observations of relatively faint, and sometimes featureless, red auroral emissions in terms of SAR arcs should perhaps be regarded merely as an interesting suggestion, which has yet to be substantiated satisfactorily or refuted rigorously.

Before discussing the characteristics of the oriental auroral records, it might be helpful to clarify briefly the use of the term "simultaneous". In this study, the term "simultaneous" is used primarily to signify that the aurora borealis was observed from more than one East-Asian site on the same night. With this definition of simultaneity, it is possible that different auroral displays were seen in different regions of the sky at different times during the night. However, the implicit underlying assumption is that all oriental auroral displays occurring during the same night are manifestations of the same intense geomagnetic storm. When discussing the degree of simultaneity between oriental and occidental auroral observations, the definition of "simultaneous" is relaxed to include European auroral observations that occur within two days of East-Asian auroral observations.

\section{Background to simultaneous oriental auroral observations}

The ancient oriental records that describe simultaneous auroral observations on a particular night are presented in subsequent sections, in each of which the appropriate observations on that night are quoted and discussed individually. However, it is convenient to begin with some preliminary remarks regarding such general matters as the sources of the ancient oriental auroral observations, the exact locations at which observations were made, calendar conversions and observational details.

The present investigation is based largely on the new catalogue of auroral observations from China, Korea and Japan (193 BC-AD 1770) published by Yau et al. (1995). This compilation has as its nucleus the work of both Keimatsu (1970-1976) and Dai and Chen (1980). An independent search of East-Asian history for further records was also undertaken in the process of compiling the new catalogue. The letters KE at the end of the appropriate catalogue entry denote an observation derived from the papers by Keimatsu (1970-1976). Similarly, the letters DC denote an observation found in the paper by Dai and Chen (1980). This nomenclature is retained here in all quotations from the new catalogue. The original catalogue compiled by Keimatsu (19701976), which contains translations into English of individual reports, only extends in detail up to $\mathrm{AD}$ 1130; subsequent observations are merely summarised in tabular form. Moreover, many of the entries in the catalogue of Keimatsu (1970-1976) clearly relate to meteors rather than the aurora; these are indicated by reference to their rapid motion across the sky, as well as use of the term liu-hsing ("flowing star"), the normal expression for a meteor. The work of Dai and Chen (1980) is more reliable but still contains several dubious observations. These unreliable records have been expunged from the catalogue of Yau et al. (1995).

The material from the catalogue of Yau et al. (1995) has been supplemented with data from three further sources: (1) the results of a detailed search through Chinese history for a wide variety of astronomical records by Beijing Observatory (1988): these results were originally published with a limited circulation and hence were unavailable at the time Yau et al. (1995) were in the process of compiling the material for their catalogue; (2) a comprehensive catalogue of Japanese astronomical records since AD 1600 by Osaki (1994), together with a research paper on ancient aurorae seen in Japan (Matsushita, 1956); (3) our own searches in Korean chronicles.

Unless there is evidence to the contrary, it is assumed that for China the location at which an observation was made is in the vicinity of the imperial capital of the time. In quoting the records, the original name of the appropriate capital is added within square brackets 
immediately after the name of the country (e.g. [China, Pien]). However, several Chinese records originate from the provinces, sometimes far from the imperial capital. In these instances, the name of the province is given in square brackets instead (e.g. [China, Kan-su Province]). During the period covered, only two relevant records from Korea have been found. These are both included in the official history of the period and hence observation at the royal capital of the time is assumed (e.g. [Korea, Songdo]). In the case of Japan, the historical sources are much more diverse and hence the place is specified simply as Honshu, the main Japanese island (e.g. [Japan, Honshu]).

The geographic co-ordinates of the oriental capitals, provinces and regions cited in this paper are given in Table 1. The geographic locations of the imperial capitals of China have changed significantly during historical times, often implying a movement of the order of $1000 \mathrm{~km}$. For simplicity, it is assumed that each Japanese observation was made in the Kyoto Region, since Kyoto was the cultural as well as political centre of Japan throughout the period of this study. Honshu is a relatively small island compared with China and therefore the true geographic co-ordinates of Japanese sightings should not be markedly different from those given in Table 1. As already noted, it is assumed that the Korean observations were made at Songdo, the capital until AD 1392, since the two Korean observations discussed in this paper occurred before then.

The Chinese calendar, which was luni-solar, was adopted with little change in both Korea and Japan. However, in each country, years were numbered relative to the reign of the appropriate ruler. In all three countries, most years contained twelve lunar months, each of length 29 or 30 days. Every three years or so an intercalary month was inserted in order to keep the calendar in step with the seasons. Intercalation was not always practised simultaneously in China, Korea and Japan, but differences were usually slight. Days were sometimes noted from the start of each lunar month. However, a 60-day (sexagenary) cycle was also adopted. This cycle, which covered a little over two lunar months, was independent of any astronomical parameter. Its regular use, especially in China and Korea, materially assists in the conversion of dates to the Julian or Gregorian calendar. A list of the cyclical days is presented in Table 2.

Table 1. Geographic coordinates of the appropriate oriental capitals (or regions)

\begin{tabular}{llll}
\hline Honshu (Kyoto) $^{\mathrm{a}}$ & Japan & $35^{\circ} 00^{\prime} \mathrm{N}$ & $136^{\circ} 00^{\prime} \mathrm{E}$ \\
Kan-su Province $^{\mathrm{a}}$ & China & $37^{\circ} 00^{\prime} \mathrm{N}$ & $103^{\circ} 00^{\prime} \mathrm{E}$ \\
Lin-an & China & $30^{\circ} 15^{\prime} \mathrm{N}$ & $120^{\circ} 10^{\prime} \mathrm{E}$ \\
Pien & China & $34^{\circ} 47^{\prime} \mathrm{N}$ & $114^{\circ} 20^{\prime} \mathrm{E}$ \\
Shang-ching & China & $43^{\circ} 59^{\prime} \mathrm{N}$ & $119^{\circ} 20^{\prime} \mathrm{E}$ \\
Shan-hsi Province $^{\mathrm{a}}$ & China & $36^{\circ} 00^{\prime} \mathrm{N}$ & $111^{\circ} 00^{\prime} \mathrm{E}$ \\
Shan-tung Province & China & $36^{\circ} 00^{\prime} \mathrm{N}$ & $118^{\circ} 00^{\prime} \mathrm{E}$ \\
Songdo & Korea & $37^{\circ} 58^{\prime} \mathrm{N}$ & $126^{\circ} 34^{\prime} \mathrm{E}$ \\
\hline
\end{tabular}

${ }^{a}$ Denotes approximate coordinates (given to the nearest degree)
A computer program has been devised by the authors to effect rapid date conversion; to the Julian calendar prior to $\mathrm{AD} 1582$ October 5 and to the Gregorian calendar thereafter.

Most auroral records give only a very general time of night, if any indication at all. Occasionally the night watches (keng) are used. The interval from dusk (defined as $37 \mathrm{~min}$ after sunset) to dawn (the same time before sunrise) was divided into five equal night watches. Near the equinoxes, the watches were each equal to about $2.2 \mathrm{~h}$ but at the solstices they could range in length from about $1.7 \mathrm{~h}$ in summer to about $2.6 \mathrm{~h}$ in winter. The third watch was centred on midnight. Sometimes the double hours (shih) were utilised instead. These were twelve regular divisions of the day and night. The night-time hours were $y u$ (17$19 \mathrm{~h})$; hsu (19-21 h); hai (21-23 h); tzu (23-1 h); ch'ou (1-3 h); yin (3-5 h); and mao (5-7 h). Very occasionally, the time unit known as the k'o (equal to about $15 \mathrm{~min}$ ) was also used.

Azimuthal directions were usually very crude, no more than N, NE, E, SE, S, SW, W and NW. Sometimes an angular extent of the auroral display is given. This is usually quoted either in terms of $c h$ 'ih (roughly $1^{\circ}$ ) or chang (approximately $10^{\circ}$ ). It should be noted that there is no explicit plural in Classical Chinese. Unless the number of items is specified, whether the singular or plural is intended can only be judged from the context.

Some oriental records mention the constellation(s) in which an auroral display was visible. These are identified here by italicised names beginning with a capital letter, e.g. Pei-tou (see Sect. 5) and Tzu-wei (see Sect. 4).

Another important physical variable is the phase of the Moon at the time of a particular auroral display. In general, faint auroras are more likely to be detected near new Moon. The phases and elongations of the Moon presented in the following sections have been calculated using a specially designed computer program. Where the oriental record gives the day of the lunar month (a frequent occurrence), we have noted that there is invariably good correspondence between this day and our calculated age of the Moon.

\section{Simultaneous auroral observations on AD 1101 January 31}

The descriptions of the simultaneous oriental auroral observations during the night of $\mathrm{AD} 1101$ January 31 may be translated as follows (the oriental book titles are in italics):

(ia) [China, Pien] Chien-chung Ching-kuo reign-period, 1st year, 1st month, 1st day. "In the evening, a red vapour arose in the NE. It extended across and filled the western sky. Some time later, two white vapours appeared within it. When the red vapour was about to disperse, two black vapours appeared at its side." (Sungshih, 64) (DC192, KE310)

(ib) [China, Pien] Chien-chung Ching-kuo reign-period, 1st year, 1st month, day jen-hsu (59), the 1st day of the month. "A red vapour arose in the NE. It extended to the SW. Within it appeared a white vapour. When it was about to disperse, a black vapour was at its side." (Sung-shih, 19) 
Table 2. The Chinese sexagenary cycle

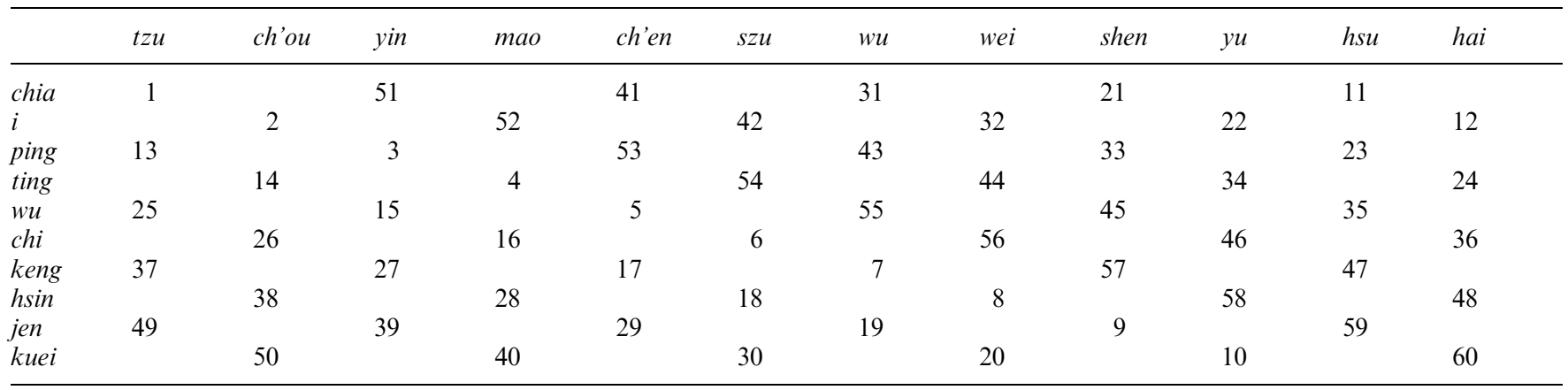

(ii) [North China, Shang-ching] Shou-ch'ang reign-period, 7th year, 1st month, day jen-hsu (59), the 1st day of the month. "Tonight, a white vapour like silk descended from the sky. Dark clouds arose in the NW; they flew very fast with a sound. In the N, there were blue, red, black and white vapours entangling themselves and falling down." (Liao-shih, 26) (DC192, KE310)

[N.B. Liao (principal capital Shang-ching) was a semi-nomadic kingdom in what is now Inner Mongolia.]

(iii) [Korea, Songdo] King Sukjong, 6th year, 1st month, day jen-hsu (59), the 1st day of the month. "At night, a red vapour pointed from the $\mathrm{N}$ towards the $\mathrm{W}$ like a silk cloth covering the sky. At times, a white vapour also appeared. It lasted a long time, then it dispersed." (Koryo-sa, 53) (DC192, KE310)

The two records from China proper (capital: Pien, modern name K'ai-feng) are from different sections of the same history (Sung-shih) and are not necessarily independent of one another. However, they are definitely independent of the records from North China (site: Shang-ching in Inner Mongolia, very close to the modern town of Pa-lin Tso-ch'i) and Korea (capital: Songdo, modern name Kaesong), which in turn are independent of each other. In addition, there is good accord between the three independent oriental auroral descriptions.

No incontrovertible evidence has yet been found for European auroral observations during the night of $\mathrm{AD}$ 1101 January 31. However, Vyssotsky (1949), in his translation of astronomical records in the medieval Russian chronicles, cites the following account from the Lavrentievsky annals:

"(6610) During this year there was a sign in the sky, in the month of January, on the 29th (day), and it lasted three days. A glow of a big fire was visible in the east, south, west and north, and the light continued through the night, as if a full Moon were shining."

Vyssotsky notes that similar records are found in two other Russian chronicles: Niconovsky and Voskresensky. The year 6610, which is expressed in terms of the Byzantine Era of Creation (5508 BC), is equivalent to $\mathrm{AD}$ 1102. However, Vyssotsky notes that in the various chronicles, although the day of the month is usually accurate, the year "may be in error by as much as two or three years". The exact agreement between the month (January) and the day (31) in the three independent East-Asian records and the Russian account (i.e. the last day of visibility) raises the possibility of a one-year error in the Russian chronicles.
The phase and elongation of the Moon at 16:00 UT (which corresponds approximately to midnight in East Asia) on the night of AD 1101 January 31 were 0.004 and $7^{\circ} \mathrm{E}$, respectively. These details accord well with the Chinese, North Chinese and Korean reports that the observations were made on the 1st day of the lunar month. Therefore, the three independent oriental auroral observations during this night were definitely made at a time when unaided-eye auroral observations would not have been hindered by the presence of moonlight (i.e. the observations were essentially made during a "dark-Moon interval").

\section{Simultaneous auroral observations on AD 1138 October 6}

The descriptions of the simultaneous oriental auroral observations during the night of AD 1138 October 6 may be translated as follows:

(ia) [China, Lin-an] Shao-hsing reign-period, 8th year, 9th month, day chia-shen (21), the 1st day of the month. "At night, there was a red vapour like fire. It appeared within the wall of Tzuwei." (Sung-shih, 60) (DC256)

(ib) [China, Lin-an] Shao-hsing reign-period, 8th year, 9th month, day chia-shen (21), the 1st day of the month. "A red vapour appeared at the wall of Tzu-wei." (Sung-shih, 64) (DC256)

(ic) [China, Lin-an] Shao-hsing reign-period, 8th year, 9th month, day chia-shen (21), the 1st day of the month. "At the true $\mathrm{N}$, there was a red vapour like the shadow of fire." (Wen-hsien T'ung-k'ao, 294) (DC256)

(ii) [Korea, Songdo] King Injong, 16th year, 9th month, day chia-shen (21). "At night, a red vapour was emitted from the NE direction." (Koryo-sa, 53) (DC256)

Although the three records from China (capital: Linan, modern name Hang-chou) are not necessarily independent of one another, the record from Korea (Songdo) is definitely independent of the other three. Moreover, there is again a high level of agreement between the independent oriental auroral descriptions. The single Korean record refers to a red vapour emitted from the northeastern direction. The three Chinese records imply that a red vapour was seen in the northern direction. Tzu-wei ("Purple Palace") is an approximately elliptical region roughly centred on the north celestial pole; the "walls" extend from about $15^{\circ}$ to $30^{\circ}$ from the pole itself. At a geographic latitude of $30^{\circ} \mathrm{N}$ (Lin-an; see 
Table 1), the elevation of $T z u-w e i$ would be about $30^{\circ} \pm 20^{\circ}$.

According to a list of 402 northern lights observed in Bohemia, Moravia and Slovakia from 1013 till 1951, compiled by Seydl (1954), the aurora borealis was observed from at least one site in Eastern Europe during the night of $\mathrm{AD} 1138$ October 6 and again on the following night. The translation of the relevant record, as presented by Seydl (1954) is as follows:

"(AD 1138 October 6) Towards evening living red forms emerged in the North. The same occurred the following night and on the 7th of October they emerged at dawn in the reddening morning sky."

Despite the apparent confusion over dates, it is likely that red auroral displays were seen in the north on both October 6 and 7. In October, the Sun would set a little to the south of west so that as the "living red forms" emerged in the north it seems most unlikely that they should be attributed to an atmospheric or meteorological phenomenon. Indeed, the use of the phrase in quotation marks may well signify dynamic movement, which would probably favour an interpretation in terms of an active auroral display. The statement in the original record (reported by A. Strnad and translated by him into German from the original Latin) that "the same (phenomenon) occurred the following night" supports this latter interpretation.

In the catalogue of occidental auroral observations compiled by Link (1962), reference is made to a reddened northern sky in England at twilight on October 7. A translation (from Latin) of the relevant passage in The Chronicle of John of Worcester (McGurk, 1998, p. 257) reads as follows:

"On the seventh day of October, on the twenty-ninth moon, at dusk, on the sixth night of the week, the whole firmament to the north appeared red, and many rays of various colours were seen, blending and disappearing. These signs may have portended the great shedding of blood in Northumbria and many other places in England, of which we have spoken."

The authors have confirmed by computation that $\mathrm{AD}$ 1138 October 7 was a Friday, which accords with the quoted text in The Chronicle of John of Worcester. Hence the date of the auroral observation in England is apparently one day after the East-Asian date, which suggests tentatively that red auroral displays occurred at least intermittently over an interval longer than $30 \mathrm{~h}$ on this particular occasion. However, the precise duration of the red auroral displays is uncertain to the extent that there is some doubt about just when the day was considered to begin in medieval times, namely either at midnight or at sunset (Dall'Olmo, 1979). Notwithstanding this minor reservation, the red auroral displays observed in both East Asia and Europe were probably associated with an intense geomagnetic storm that lasted for more than $30 \mathrm{~h}$.

The phase and elongation of the Moon at 16:00 UT on the night of $\mathrm{AD} 1138$ October 6 were 0.005 and $9^{\circ} \mathrm{E}$, respectively. These details accord well with the Chinese reports that the observations were made on the 1st day of the lunar month. Therefore, the two independent oriental auroral observations during this night were also made at a time when unaided-eye oriental auroral observations would not have been hindered by the presence of moonlight.

\section{Simultaneous auroral observations on AD 1363 July 30}

The descriptions of the simultaneous oriental auroral observations during the night of AD 1363 July 30 may be translated as follows:

(i) [China, Shan-hsi Province] Chih-cheng reign-period, 23rd year, 6th month, day ting-szu (54). "At dusk in Chin-chou, a red light like fire was seen in the $\mathrm{N}$ direction. Within, it was interspersed with dark vapours. Also, there were two white rainbows soaring straight into Pei-tou. After a long time, then they were dispersed." (Yuan-shih, 51) (DC368)

(iia) [Japan, Honshu] Shohei reign-period, 18th year, 6th month, day ting-szu (54). "During the night, in the NE and $\mathrm{N}$ directions, there was a light similar to a distant funeral pyre. The cause was not known; some said that this was a sign of a drought." (text quoted by Kanda, 1934) (DC368)

(iib) [Japan, Honshu] Shohei reign-period, 18th year, 6th month, day ting-szu (54). "Tonight, there was a red vapour in the N and NE. Was this a sign of a severe drought?" (text quoted by Kanda, 1934) (DC368)

The official Korean chronicle, the Koryo-sa, contains no notice of this event.

Although the two records from Japan (Honshu) are probably not independent of one another, the record from China (Shan-hsi Province) is definitely independent of the two Japanese records. Moreover, there is again good accord between the independent oriental auroral descriptions. The single Chinese record refers to a red light like fire, which was seen in the northern direction. The two Japanese records make reference to a red vapour (or a light similar to a distant funeral pyre) that was observed in both the northern and northeastern directions. In this case, there is general agreement between both the colour of the auroral display and its approximate position in the sky.

No evidence has yet been found for European auroral observations during the night of AD 1363 July 30.

A noteworthy feature of these particular simultaneous auroral observations in East Asia is the fact that the aurora borealis was seen again three nights later from a separate site in China. The description of the Chinese auroral observation during the night of AD 1363 August 2 may be translated as follows:

[China, Shan-hsi Province] Chih-cheng reign-period, 23rd year, 6th month, day keng-shen (57). "At dusk, to the N of Chin-ning-lu, the sky was red. Within it, there were three white vapours like rainbows. One penetrated Pei-tou, one penetrated Pei-chi and one penetrated T'ien-huang. Not until midnight were they extinguished." (Yuan-shih, 51) (DC 369)

As for the night of July 30, the official Korean chronicle, the Koryo-sa, contains no notice of the later event on the night of August 2. Moreover, there is no evidence for Japanese observations on this latter date.

The single record from a different site in Shan-hsi Province on the night of August 2 is very similar to the Chinese and Japanese observations on the night of July 30. Explicit reference is made to a predominantly red 
auroral display on both nights, although reference is also made to "three white vapours like rainbows" within the main red auroral display in the Chinese record for the night of August 2. Similarly, the Chinese record for the night of 30 July refers to "two white rainbows", although it is not stated explicitly that these lie within the main red auroral display.

The phase and elongation of the Moon at 16:00 UT on the night of AD 1363 July 30 were 0.85 and $134^{\circ} \mathrm{W}$, respectively. However, since moonrise occurred about $3 \mathrm{~h}$ after sunset, unaided-eye auroral observations in the early evening would not have been hindered by the presence of strong moonlight. The Chinese records state specifically that the observations on both July 30 and August 2 were made "at dusk", whereas the Japanese reports give no indication of time.

\section{Simultaneous auroral observations on AD 1582 March 8}

The descriptions of the simultaneous oriental auroral observations during the night of $\mathrm{AD} 1582$ March 8 may be translated as follows:

(i) [China, Kan-su Province] Wan-li reign-period, 10th year, 2nd month, day kuei-mao (40). "In Kan-su, a red and white cloudy vapour was seen." (Ming-shih-lu, 121)

(iia) [Japan, Honshu] Tensho reign-period, 10th year, 2nd month, 14th day. "Tonight, there was a red cloudy vapour in the sky." (text quoted by Kanda, 1934) (DC738)

(iib) [Japan, Honshu] Tensho reign-period, 10th year, 2nd month, 14th day, kuei-mao (40). "At night, there was a red vapour filling the N sky." (text quoted by Kanda, 1934) (DC738)

The official Korean chronicle, the Sonjo Sillok, contains no notice of this event. However, the Korean annals are very incomplete around this date.

There is no mention of occurrence at night in the Chinese record but in view of the exact agreement in date with the two Japanese records this can be confidently assumed; it is unlikely to have been an observation of a meteorological phenomenon. The two records from Japan (Honshu) are possibly independent of one another but the record from China (Kan-su Province) is definitely independent of these two Japanese records. There is again a fair level of agreement between the independent oriental auroral descriptions, at least in the sense that explicit reference is made to a red-coloured vapour in the Chinese and (both) Japanese records.

According to the catalogue compiled by Link (1962), there were several auroral observations in Europe on the night of AD 1582 March 6. (Link, 1962, actually gives the date as AD 1582 March 16 in the Gregorian calendar, although this calendar was not introduced until October in that year.) One European historical record quoted by Link (1962) (reported by J.J. Scheuchzer in German) states that the night sky was coloured red (i.e. there is a reference to the colour of blood) over at least two cities in Switzerland. This red aurora was seen at 18:00 LT over Zürich $\left(47^{\circ} 23^{\prime} \mathrm{N}, 08^{\circ} 33^{\prime} \mathrm{E}\right)$ but by 19:00 LT it had moved to the northwest towards nearby Baden $\left(47^{\circ} 28^{\prime} \mathrm{N}\right.$, $08^{\circ} 19^{\prime}$ E). Fritz (1873) also quotes a record (attributable to B. A. Musculi and written in Latin) which indicates that an auroral display was seen from Bern $\left(46^{\circ} 57^{\prime} \mathrm{N}\right.$, $07^{\circ} 26^{\prime} \mathrm{E}$ ). Another European historical record quoted by Link (1962) (reported by R. Guggenbühl in German) refers to a blood-red aurora towards the north. Both Seydl (1954) and Link (1962) quote a record (attributable to $\mathrm{S}$. Hüttel and written in German) indicating the existence of red aurora over Bohemia and Silesia (i.e. there are references to the sky being suffused with blood and full of signs like blazing brooms or torches). These same authors also quote a record (reported by V. Březan in Czech) of a red aurora above the town of Sedlčany $\left(49^{\circ} 40^{\prime} \mathrm{N}, 14^{\circ} 26^{\prime} \mathrm{E}\right)$ in South Bohemia, starting at 17:30 LT. (Bohemia is an old province of the Czech Republic.) This particular record mentions the existence of some broad fiery or bloody clouds resembling columns, which caused the local people to suppose that a destructive fire was blazing in the vicinity. Fritz (1873) also mentions these observations but without explicit reference to Bohemia. We have adopted the policy of spelling the names of European cities, provinces and regions in exactly the same way as in the references cited.

The date of all these European auroral observations (1582 March 6) is two days earlier than the East-Asian date, which suggests tentatively that red auroral displays occurred at least intermittently over an interval longer than $40 \mathrm{~h}$ on this occasion. Therefore, these auroral displays were probably associated with an intense geomagnetic storm that lasted for more than $40 \mathrm{~h}$. The world list of polar aurorae at geographic latitudes less than $55^{\circ}$, published by Křivský and Pejml (1988), notes that Fritz (1873) cites auroral observations in Prussia on the night of 1582 March 8. The actual records listed briefly by Fritz (attributable to J.N. Frobesius and C. Kirch, and written in Latin) imply that an auroral display was seen from Prussia on the night of 1582 March 8 (although Fritz does not present the original records). If authentic, these latter European auroral observations would have been made during the same night as the auroral observations from Kan-su Province in China and Honshu in Japan.

The phase and elongation of the Moon at 16:00 UT on the night of $\mathrm{AD} 1582$ March 8 were 0.993 and $171^{\circ} \mathrm{E}$, respectively. These details accord well with the two Japanese reports, which both state that the observations were made on the 14th day of the lunar month. On this date, the full Moon rose almost due east just before sunset, although it is clear from the descriptions in the oriental historical records that strong moonlight did not preclude independent observations of auroral displays in the north from both China and Japan. Therefore, the auroral displays must have been very bright, which tends to confirm the conclusion that they were probably associated with an intense geomagnetic storm.

\section{Simultaneous auroral observations on AD 1653 March 2}

The descriptions of the two simultaneous oriental auroral observations during the night of AD 1653 March 2 may be translated as follows: 
(i) [China, Shan-tung Province] Shun-chih reign-period, 10th year, 2nd month, 3rd day. "At night, in the four directions, flames rose in the sky; they were of different sizes. After a while they turned into dark phosphorus coloured clouds." (Ts'ao-hsien-chih, 18)

(ii) [Japan, Honshu] Joo reign-period, 2nd year, 2nd month, 3rd day. "Recently, between Shimotsuma (or Shimono), Nasu and Odawara a red and white vapour appeared. It looked like a flag and the red part quickly disappeared, so it was reported." (Tokugawa Jikki)

The official Korean chronicle, the Hyonjong Sillok, contains no notice of this event.

On this occasion, there is no mention of occurrence at night in the Japanese record but in view of the exact agreement in date with the Chinese record this can again be confidently assumed. Moreover, the records from China (Shan-tung Province) and Japan (Honshu) are definitely independent of one another. Yet once again there is a reasonable level of agreement between these two independent auroral descriptions. This last statement is true in the sense that explicit reference is made in both the Chinese and Japanese records to the colour red or dark red. This conclusion is based on the very reasonable assumption that the word "flames" implies the colour "red" and the slightly more questionable assumption that the words "dark phosphorus" imply the colour "dark red". There are two allotropes of phosphorus: white (toxic and flammable) and red (nontoxic and less reactive). It seems reasonable to prefer the latter alternative, particularly as the word "phosphorus" is qualified by the adjective "dark".

No evidence has yet been found for European auroral observations on the night of AD 1653 March 2.

The phase and elongation of the Moon at 16:00 UT on the night of AD 1653 March 2 were 0.12 and $41^{\circ} \mathrm{E}$, respectively. These details confirm the Chinese and Japanese reports, which both state that the observations were made on the 3rd day of the lunar month. The young crescent Moon would have been fairly dim and would have set some three hours after sunset; therefore unaided-eye auroral observations would scarcely have been hindered by the presence of moonlight.

\section{Discussion and conclusions}

As part of a wider attempt to undertake a critical assessment of the reliability and utility of the sunspot and auroral observations recorded in various oriental histories (see Willis et al., 1996a, b), attention is focused in this study on early simultaneous observations of the aurora borealis from spatially separated sites in East Asia. Such simultaneous oriental auroral observations are relatively rare; only five examples of simultaneous observations that are indisputably independent have been found during the interval 193 BC-AD 1700. These occurred during the nights of AD 1101 January 31, AD 1138 October 6, AD 1363 July 30, AD 1582 March 8 and AD 1653 March 2. Four further similar events occurred in the interval AD 1700-1900. However, as a result of the general increase in the availability of recorded information with the passage of time, the oriental and occidental historical records associated with these four later events are so detailed and extensive that they warrant consideration in a separate publication.

On the night of AD 1101 January 31, the aurora borealis was observed simultaneously and independently from sites in China, North China and Korea. The aurora borealis may also have been seen on this same night from a site in Russia. On the night of AD 1138 October 6, the aurora borealis was observed simultaneously and independently from sites in China and Korea. The aurora borealis was definitely observed on the following night from at least one site in England and may also have been observed on the same night as in East Asia from at least one site in Eastern Europe. On the night of AD 1363 July 30 , the aurora borealis was observed simultaneously and independently from sites in China and Japan. On the night of AD 1582 March 8, the aurora borealis was again observed simultaneously and independently from sites in China and Japan. However, on this latter occasion, it was definitely observed two nights earlier from several sites in Europe and there is some evidence that it was also observed in Europe on the same night as in East Asia. On the night of $\mathrm{AD} 1653$ March 2, the aurora borealis was observed simultaneously and independently from sites in China and Japan.

In each of these five examples of simultaneous auroral observations, there is a good level of agreement between the independent auroral descriptions recorded in the oriental histories. This good agreement extends from the colour of the auroral display, which was predominantly red in all five cases, to its position in the sky, which was usually in a northerly direction (N, NE or NW). In two examples (AD 1138 and $\mathrm{AD} 1363$ ), reference is also made in the Chinese records to the constellation (or constellations) in which the auroral display was visible, which provides complementary (and largely confirmatory) information on the position of the auroral display in the sky. Furthermore, in the two (possibly three) examples for which auroral displays occurred in Europe within two days of recorded auroral displays in East Asia (AD 1138, AD 1582 and possibly AD 1101), the relevant European histories also mention red auroral displays in the north. The fact that most records refer to red auroral displays being seen predominantly in northerly directions (N, NE or NW) is consistent with the well-known overall increase in frequency of occurrence of auroral displays with increasing magnetic latitude, at least up to the auroral zone (Legrand and Simon, 1989). Moreover, since auroral displays are relatively infrequent at mid-latitudes, the five examples of simultaneous oriental auroral observations presented here were probably associated with intense geomagnetic storms. This latter conclusion is corroborated by the existence of recorded auroral displays at European longitudes, within two days of the auroral displays in East Asia, on two (possibly three) out of the five occasions.

The inclusion of occidental auroral observations that do not occur during exactly the same night as the oriental auroral observations requires some further clarification. It should perhaps be mentioned again that Fukushima et al. (1987) regarded occidental and orien- 
tal auroral observations as being simultaneous if they occurred within two days of each other. In the case of the oriental auroral observations, however, occurrence during the same night has been invoked as a strict condition for simultaneity in this study. This strict condition has been imposed in the interests of scientific stringency. For example, the East-Asian auroral observations refer to a comparatively small geographic region, in a global context, for which occurrence during the same night represents the most obvious, logical and exact criterion. However, the level of cloud cover can vary markedly over this geographic region. Therefore, the existence of simultaneous auroral observations necessarily implies virtually clear skies at all the corresponding East-Asian observing sites (i.e. the level of cloud cover at each site must have been insufficient to preclude auroral observations). A similar statement applies to the European auroral observations.

On two (possibly three) of the five occasions of strictly simultaneous and indisputably independent oriental observations of the aurora borealis, auroral displays were also seen in Europe within two days of the simultaneous auroral displays in East Asia. In general, there is a good level of agreement between the auroral descriptions recorded strictly simultaneously in Chinese, Japanese and Korean histories and those recorded essentially simultaneously in European histories. This global coincidence (within about two days) of simultaneous and independent observations of the aurora borealis, from both Europe and East Asia, suggests that a substantial number of the mid-latitude auroral displays recorded in the oriental histories were associated with intense geomagnetic storms.

In conclusion, the rare occurrence of simultaneous and independent auroral observations from spatially separated sites in East Asia, as described in historical records from China, Japan and Korea, provides virtually incontrovertible evidence for the actual existence of auroral displays on these rare occasions. The high level of agreement between the independent auroral descriptions substantiates this conclusion; this agreement applies both to the colour(s) of the auroral display and its position in the sky. The reliability of the ancient oriental auroral records on such rare occasions tends to confirm their overall reliability at other times. Similarly, the occurrence of occidental and oriental auroral observations on the same night, or on contiguous nights, tends to confirm the reliability of both the oriental and occidental records. Nevertheless, some reservations must still be expressed regarding the reliability of the very large number of presumed Korean auroral (or SAR-arc) records between about $\mathrm{AD} 1510$ and 1560 and again for several years around $\mathrm{AD}$ 1625. Further research is required to resolve this enigma.

Acknowledgements. The authors thank Dr M.S. Dillon, Mr J.P.C. Moffett and Mr D.F. Starr for help with the translation of records written in Chinese and Japanese. They also thank Dr M.E. Dieckmann, Dr N.G.J. Gazey and Dr I.W. McCrea for help with the translation of records written in German. Helpful comments by a referee have resulted in several important clarifications.
The Editor-in-Chief thanks G. Siscoe and T. Oguti for their help in evaluating this paper.

\section{References}

Beijing Observatory (Ed), Zhongguo Gudai Tianxiang Jilu Zongji (A Union Table of Ancient Chinese Records of Celestial Phenomena) (in Chinese), Kexue Jishi Chubanshe, Kiangxu, pp 27-60, 1988.

Dai Nian-zu, and Chen Mei-dong, Historical auroral data from China, Korea and Japan from the legendary period to AD 1747 (in Chinese), Kejishiwenji, 6, 87-146, 1980.

Dall'Olmo, U., An additional list of auroras from European sources from 450 to 1466 AD, J. Geophys. Res., 84, 1525-1535, 1979.

Fritz, H., Verzeichniss Beobachteter Polarlichter, C. Gerold's Sohn, Wien, 1873.

Fritz, H., Das Polarlicht, F. A. Brockhaus, Leipzig, 1881.

Fukushima, N., A. Egeland, L.-Z. Jin, Q.-L. Liu, S. M. Silverman, and M. Teboul, Secular variation of the geomagnetic axis in historic time known from the comparison of ancient records of aurorae observed in the Occident and Orient, Proceedings of IAGA Symposium on Space-Time Structure of the Geomagnetic Field (held at Wittenberg, Germany, September 1986), Report 21, Heinrich-Hertz-Institute, Berlin, pp 55-58, 1987.

Gustafsson, G., N. E. Papitashvili, and V. O. Papitashvili, A revised corrected geomagnetic coordinate system for Epochs 1985 and 1990, J. Atmos. Terr. Phys., 54, 1609-1631, 1992.

Kanda, S., Nihon Temmon Shiryo (Japanese Historical Records of Celestial Phenomena) (in Japanese), Tokyo, 1934.

Keimatsu, M., A chronology of aurorae and sunspots observed in China, Korea and Japan, Annals of Science, Kanazawa University, Part I, 7, 1-10, 1970; Part II, 8, 1-16, 1971; Part III, 9, 136, 1972; Part IV, 10, 1-32, 1973; Part V, 11, 1-36, 1974; Part VI, 12, 1-40, 1975; Part VII, 13, 1-32, 1976.

Keimatsu, M., N. Fukushima, and T. Nagata, Archaeo-aurora and geomagnetic secular variation in historic time, J. Geomagn. Geoelectr., 20, 45-50, 1968.

Kozyra, J. U., A. F. Nagy, and D. W. Slater, High-altitude energy source(s) for stable auroral red arcs, Rev. Geophys., 35, 155-190, 1997.

Křivský, L., and K. Pejml, World list of polar aurorae $<55^{\circ}$ and their secular variations, Part II, Astron. Inst. Czech. Acad. Sci., 75, 32-68, 1988.

Legrand, J.-P., and P. A. Simon, Solar cycle and geomagnetic activity: a review for geophysicists. Part I. The contributions to geomagnetic activity of shock waves and of the solar wind, Ann. Geophysicae, 7, 565-578, 1989.

Link, F., Observations et catalogue des aurores boréales apparues en Occident de -626 à 1600, Geofys. Sbornik, 10, 297-392, 1962.

Matsushita, S., Ancient aurorae seen in Japan, J. Geophys. Res., 61, 297-302, 1956.

McGurk, P., The Chronicle of John of Worcester, Vol. III, Clarendon Press, Oxford, 1998.

Oguti, T., The auroral zone in historic times - the northern UK was in the auroral zone 300 years ago, J. Geomagn. Geoelectr., 45, 231-242, 1993a.

Oguti, T., A note on the auroral frequency charts by Fritz and Vestine, J. Geomagn. Geoelectr., 45, 449-454, 1993 b.

Oguti, T., and A. Egeland, Auroral occurrences in Norwegian archives, J. Geomagn. Geoelectr., 47, 353-359, 1995.

Osaki, S., Kinsei Nihon Temmon Shiryo (Pre-Modern Japanese Historical Records of Celestial Phenomena) (in Japanese), Hara Shobo, Tokyo, 1994.

Roach, F. E., and J. R. Roach, Stable $6300 \AA$ auroral arcs in midlatitudes, Planet. Space Sci., 11, 523-545, 1963.

Seydl, O., A list of 402 northern lights observed in Bohemia, Moravia and Slovakia from 1013 till 1951, Geofys. Sbornik, 2, 159-194, 1954. 
Vestine, E. H., The geographic incidence of aurora and magnetic disturbance, northern hemisphere, Terr. Magn. Atmos. Electr., 49, 77-102, 1944.

Vyssotsky, A. N., Astronomical records in the Russian chronicles from 1000 to $1600 \mathrm{AD}$, Meddelanden. fran Lunds Astronomiska Observatorium, Ser. II, (126): Historical Papers, No. 22, 1949.

Willis, D. M., V. N. Davda, and F. R. Stephenson, Comparison between Oriental and Occidental sunspot observations, Q. J. R. Astron. Soc., 37, 189-229, 1996 a.
Willis, D. M., F. R. Stephenson, and J. R. Singh, Auroral observations on AD 1770 September 16: the earliest known conjugate sightings, Q. J. R. Astron. Soc., 37, 733-742, $1996 \mathrm{~b}$.

Yau, K. K. C., F. R. Stephenson, and D. M. Willis, A Catalogue of Auroral Observations from China, Korea and Japan (193 BC-AD 1770), Rutherford Appleton Laboratory Technical Report RAL-TR-95-073, December 1995.

Zhang, Z., Korean auroral records of the period AD 1507-1747 and the SAR arcs, J. Brit. Astron. Assoc., 95, 205-210, 1985. 